\title{
Research on the Strength Variation of Root-Clay Systems under Freeze-Thaw Action
}

\author{
Lin Yang, ${ }^{1}$ Hengxing Wang, ${ }^{1}$ Chunpeng Han, ${ }^{1}$ Hong Guo, ${ }^{2}$ \\ Yafeng Gong, ${ }^{3}$ and Yulong $\mathrm{He}^{3}$ \\ ${ }^{1}$ School of Civil Engineering, Northeast Forestry University, Harbin 150040, China \\ ${ }^{2}$ Beijing Municipal Engineering Research Institute, Beijing 100037, China \\ ${ }^{3}$ School of Transportation, Jilin University, Changchun 130025, China \\ Correspondence should be addressed to Yulong He; 852142119@qq.com
}

Received 16 June 2017; Accepted 15 August 2017; Published 3 October 2017

Academic Editor: Carlo Santulli

Copyright (C) 2017 Lin Yang et al. This is an open access article distributed under the Creative Commons Attribution License, which permits unrestricted use, distribution, and reproduction in any medium, provided the original work is properly cited.

\begin{abstract}
The aim of this paper is to study the influence of an effective root system of rhizome plants on the reinforcement of slope soil under freeze-thaw conditions. This study focused on the mechanical properties between roots and clay in the root system of four plant species from different regions of China (northeast, northern, central, and southern areas): Setaria viridis, Eleusine indica, Zoysia japonica, and Carex leucochlora. Based on the interfacial friction effects between the plant roots and the soil, pull-out tests and unconfined compressive strength tests were conducted on the reinforced soil system for varying numbers of freeze-thaw cycles. Several stages of the pull-out process of the root system in clay are explicitly proposed based on the interfacial friction test results. The results showed that the friction effect between Zoysia japonica roots and the soil was the most significant and that these roots had the best reinforcement effect. In contrast, the friction and reinforcement effects between Setaria viridis roots and the soil were the worst, and the resulting unconfined compressive strength was the smallest. However, the freeze-thaw resistance ability of the Setaria viridis and soil system was stronger than that of the Zoysia japonica system.
\end{abstract}

\section{Introduction}

Road traffic construction in China is developing rapidly. During construction, natural vegetation is destroyed, and serious soil erosion occurs. Plant slope protection technology provides the dual effects of preventing landslides and enhancing landscaping and is widely used in roadbed slope protection projects and in sandstorm control projects. In the 1930s, the first plant slope protection projects were conducted. Due to their positive reinforcement and ecological effects, they have been widely utilized throughout the world. Currently, due to the gradual deterioration of the ecological environment and the positive ecological effects of vegetative slope protection technology, plant slope protection has received increasing attention worldwide. The main principle of soil reinforcement and slope protection is to utilize the interactions between plant root tendons and the soil to reinforce shallow soil and anchor deep soil; in addition, the direction and traction of the root systems are controlled to significantly improve the soil strength and wind and water erosion resistance and to improve the slope stability.

To understand the mechanisms of plant slope protection, many experimental studies and theoretical analyses have been performed, and many research achievements have been accomplished through these efforts. These studies have mainly focused on the mechanical mechanisms of soil reinforcement by plant root systems. A few scholars have studied the interfacial friction effects between different plant roots and soils and the effects of different influencing factors on root reinforcement (RR) by experimenting with characteristic plants from different areas. Mickovski et al. reinforced soil with willows and found a strong correlation between the soil cover and shear strength [1]. Loades et al. conducted soil strengthening studies using barley roots 
with different densities [2]. Veylon et al. performed direct shear tests using three tree species from the high-slope afforestation project in Yunnan and quantified the effect of the soil moisture content on soil reinforcement [3]. Bordoni et al. quantitatively evaluated the soil reinforcement provided by a grape root system and the reinforcement effects of using different numbers of grape roots on the slope stability under rainfall conditions [4]. Burylo et al. compared the enhanced soil cohesion during early stages using six plant roots from the southern French Alps [5]. Voottipruex et al. studied the effect of a composite RR system on slope stability [6]. Saifuddin and Osman found that white cephalosporins had root systems with excellent hydrodynamic properties and could strengthen the soil when planted along a slope [7].

Another group of experts has discussed the reinforcement mechanisms of root systems in soil by combining statistical and mechanical methods. The W \& W model established by Waldron and $\mathrm{Wu}$ can effectively evaluate the potential reinforcement of plant roots within soil and provide a clear description of the relationship between a root system and the soil $[8,9]$. Bourrier et al. established a numerical model for the direct shear tests of discrete soils and determined the interaction mechanisms of various reinforced soils [10]. Kim et al. used a vertical RR model to quantify the rootto-soil enhancement [11]. Mao et al. used a finite element method and discrete element method to simulate threedimensional direct shear tests to evaluate the RR model and compare the two numerical methods [12]. Docker and Hubble simultaneously measured the pull-out strength and tensile strength of roots, used the developed model to calculate the simultaneous root tendon failure of all the roots in the shear plane, and then estimated the validity of the model [13]. Wu applied the analysis model for soil reinforcement by plant roots, carried out field tests, and compared the test data with the theoretical model to demonstrate the accuracy of the model [14]. Schwarz et al. proposed an empirical analysis model and systematically studied the effect of root stress on soil compression [15]. Hales and Miniat evaluated the effects of dynamic changes in the tensile strength of roots on the cohesion in the infinite-slope stability model [16]. Previous studies have shown that using plant roots to reinforce soil slopes can effectively improve the soil slope stability. However, all the studies mentioned above, including the field shear tests, considered only the interfacial action between the soil and plant roots under specific conditions, while ignoring possible changes in the root tendons after varying numbers of freeze-thaw cycles. Therefore, this paper utilized representative plant roots for RR in subgrade slopes at different latitudes in China and measured their tensile strength and unconfined compressive strength in soil under different freeze-thaw cycles. On the basis of the above analysis, the soil reinforcement mechanisms of the plant roots and the influence of freeze-thaw cycles on the strength of the plant root-reinforced soil are discussed. The objectives were (1) to identify plant roots that can effectively strengthen the soil under freeze-thaw cycles and (2) to determine the mechanism of plant RR of clay under freezethaw cycles.

\section{Material Selection}

2.1. Selection of Plant Root Tendons. China has a wide range of latitudes and diverse climates; hence, a vast and diverse range of plants are distributed throughout China. To reflect the varying behaviors of plant roots within soil under freezethaw conditions, roots were selected from Harbin, Dongying, Hefei, and Shaoyang. The geographical locations of the selected root sites are shown in Figure 1.

The selected plants are commonly used to protect the subgrade slopes of roads, and the four plants used in this study in geographical order from north to south are as follows: Setaria viridis, Eleusine indica, Zoysia japonica, and Carex leucochlora. Setaria viridis is an annual gramineous herbaceous plant with whisker-like roots, which are typical of the supporting roots of tall plants, and has a good ability to strengthen clay loams and loosened sandy loams that are rich in humus. Echinacea is an annual gramineous herbaceous plant with extremely developed roots and is a great plant for soil conservation. Zoysia japonica, a perennial gramineous herbaceous plant with a horizontal root system and slim, fragile roots, has a strong resistance to drought, alkalis, and pests. In addition, this plant is resistant to barren landscapes, trampling, and varying amounts of water. Carex leucochlora is a perennial herb with short rhizomes and remains green throughout the year. The roots of these four plants are shown in Figure 2.

Normal plants growing in fields were selected. The plants were enclosed in a fixed area, and soil columns with root samples along the boundary of the fixed area were dug up. The collected root systems were tested by measuring the distribution density, longitudinal elongation gradient rate, average length, and average diameter of the root system. The root distribution density was calculated using

$$
\begin{aligned}
& \text { Root amount } \\
& =\frac{\text { the dried root mass included by the composite }(\mathrm{mg})}{\text { the volume of the composite }\left(\mathrm{cm}^{3}\right)},
\end{aligned}
$$

where the volume of the composite is the volume of the shear box.

The length, diameter, and longitudinal elongation gradient of the root system were measured as follows. Twenty parts were randomly sampled after the plant root was cut, and the lengths and diameters of the roots were measured from images of the ends and the middle sections of the root samples using a digital microscope at 500x magnification (Figure 3). The average value of three measurements was taken as the average diameter of a single root. The longitudinal elongation gradient of the root was calculated using (2). Statistical analysis of the 20 root systems was conducted. The results of the analysis are shown in Figure 4, and the statistical analysis and average parameters of the plant root system are shown in Table 1 . The obvious discrete points were removed.

$$
k=\frac{D_{s}-D_{e}}{l}
$$




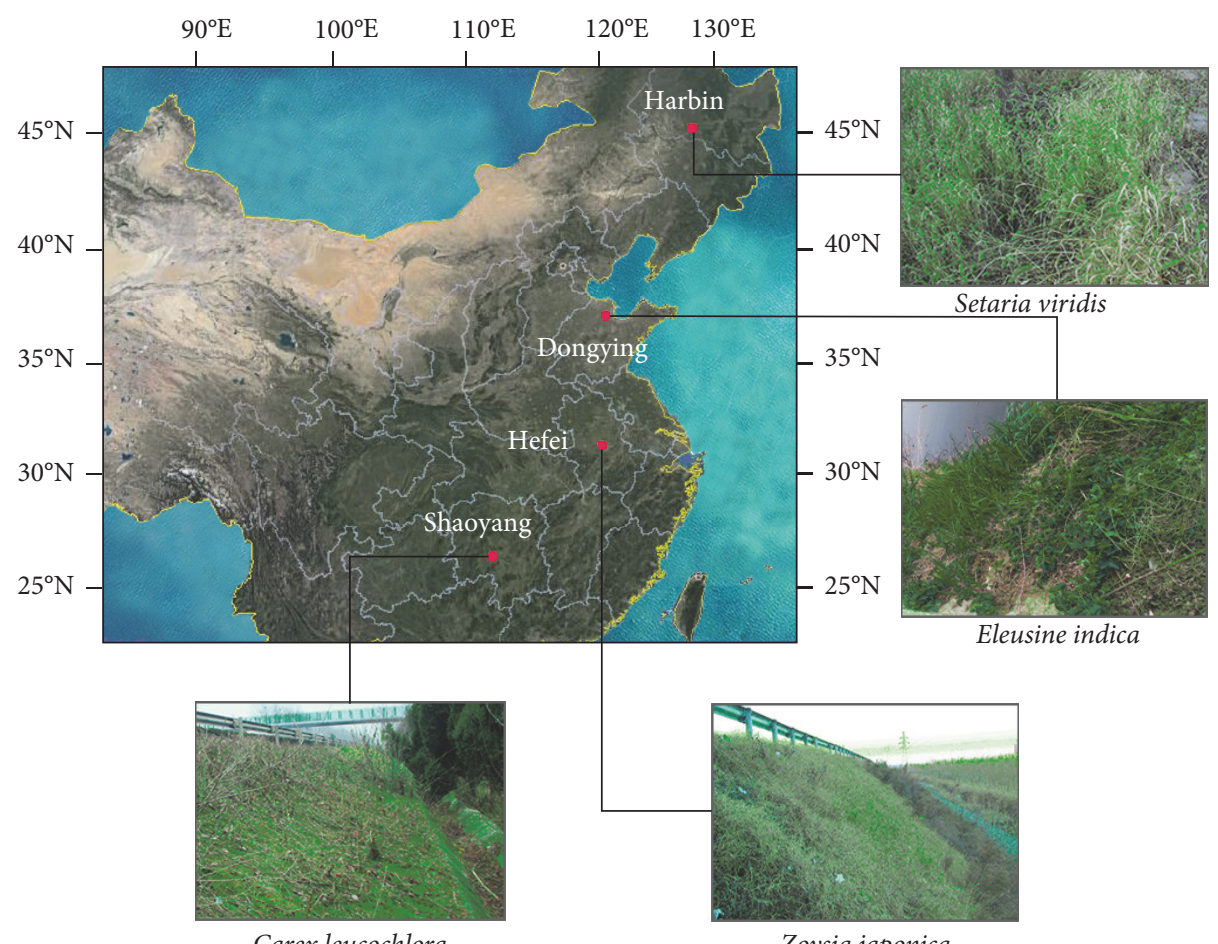

Carex leucochlora

Zoysia japonica

FIGURE 1: Selected root sites.

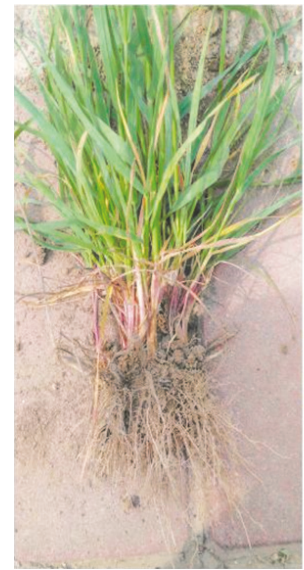

Eleusine indica

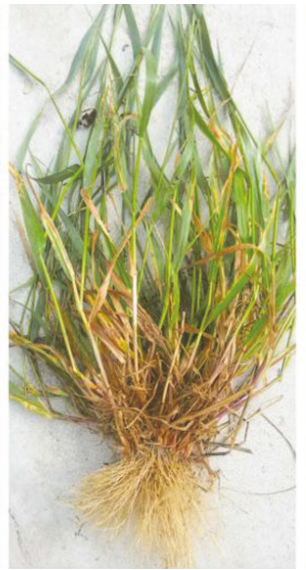

Carex leucochlora

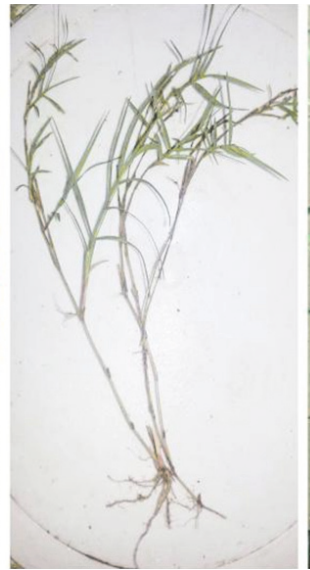

Zoysia japonica

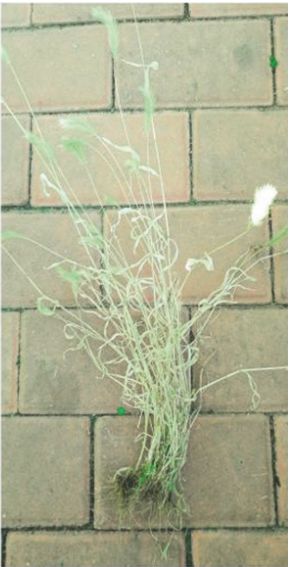

Setaria viridis

Figure 2: Plant roots.

where $k$ is the longitudinal elongation gradient, $D_{s}$ is the diameter of the initial root, $D_{e}$ is the diameter of the initial root, and $l$ is the length of the root.

2.2. Experimental Soil Samples. The plant RR technology in the project is mainly applied to improve the stability of the high fill slope of the expressway and the erosion resistance. Therefore, the soil samples used in the experiment were composed of subgrade soil from a road in Harbin. The soil samples were yellow and had a certain viscosity, and the soil type was silty clay. Basic soil tests were performed on the selected soil samples, and the basic physical and mechanical parameters are shown in Table 2.

\section{Experimental Methods and Programs}

3.1. Experimental Program. To investigate the reinforcement ability of different types of plant roots in soil under the action of freezing and thawing, the tensile strength of the system was investigated by conducting pull-out experiments between the root systems of single-root plants and soil under freeze-thaw cycles. Then, unconfined compressive strength tests were conducted to verify the effects of different plant 


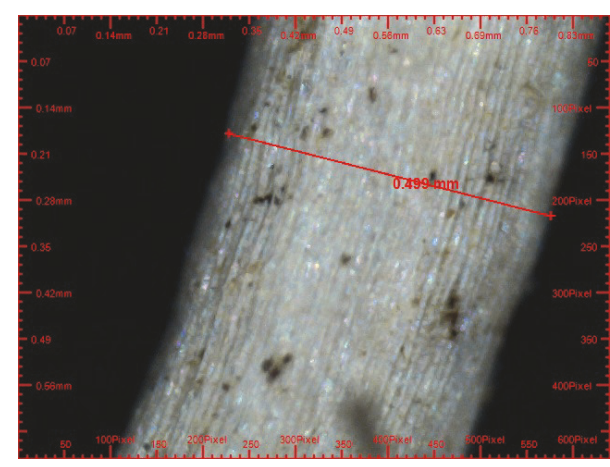

(a) Eleusine indica

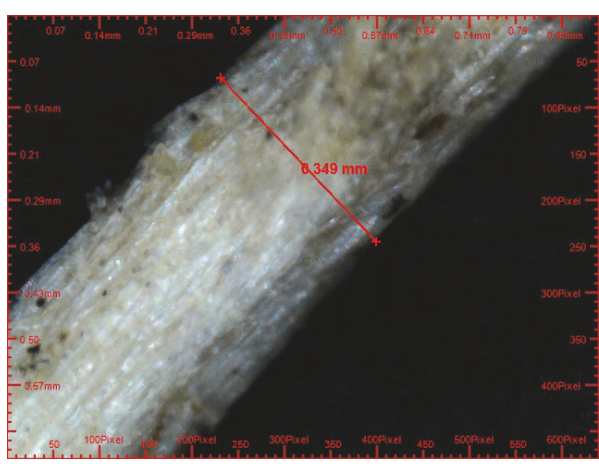

(c) Zoysia japonica

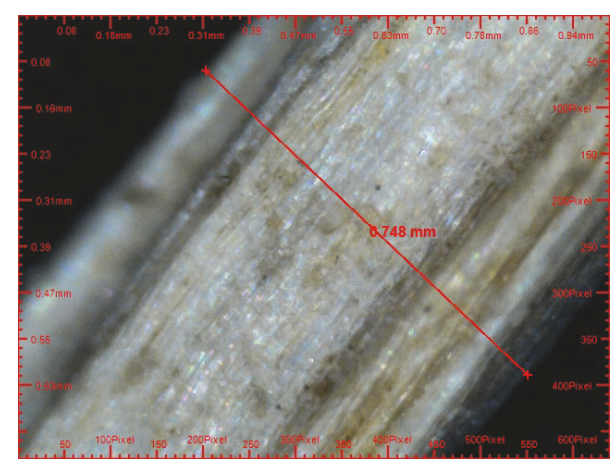

(b) Carex leucochlora

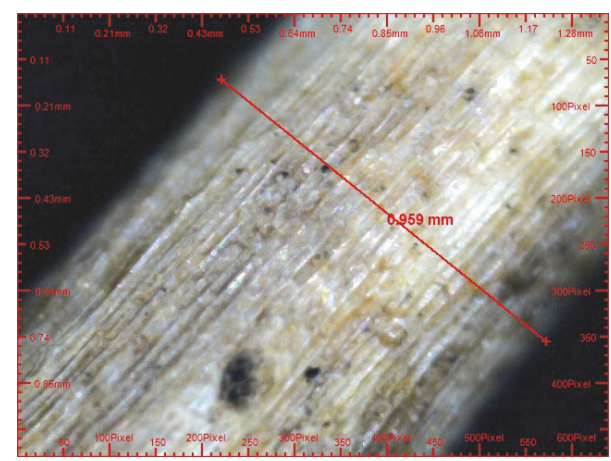

(d) Setaria viridis

FIGURE 3: Schematic diagram of the root diameter measurement.

TABle 1: Parameters of the roots.

\begin{tabular}{lcccc}
\hline Root type & $\begin{array}{c}\text { Root density } \\
(\%)\end{array}$ & $\begin{array}{c}\text { Average diameter } \\
(\mathrm{mm})\end{array}$ & $\begin{array}{c}\text { Average length } \\
(\mathrm{mm})\end{array}$ & $\begin{array}{c}\text { Longitudinal } \\
\text { elongation gradient } \\
(\%)\end{array}$ \\
\hline Zoysia japonica & $0.46 \%$ & 0.379 & 68 & $0.334 \%$ \\
Carex leucochlora & $0.23 \%$ & 0.505 & 112 & $0.175 \%$ \\
Eleusine indica & $0.20 \%$ & 0.742 & 95 & $0.295 \%$ \\
Setaria viridis & $0.17 \%$ & 0.983 & 81 & $0.790 \%$ \\
\hline
\end{tabular}

TABLE 2: Physical and mechanical parameters of the soil.

\begin{tabular}{|c|c|c|c|c|c|}
\hline Liquid limit/\% & Plastic limit/\% & Plasticity index & Maximum dry density $/\left(\mathrm{g} \cdot \mathrm{cm}^{-3}\right)$ & Best moisture content $/ \%$ & Specific gravity \\
\hline 34.1 & 22.2 & 11.9 & 1.92 & 11.2 & 2.66 \\
\hline
\end{tabular}

roots on the soil reinforcement. The design scheme for the pull-out tests between the root systems of the singleroot plants and soil is shown in Table 3. The scheme for the unconfined compressive strength tests was developed in accordance with the scheme for the pull-out tests, and the root biomass content of the plant roots was consistent with the root distribution density of the plant roots. To reflect the strengthening effect of the plant root systems on the soil strength under freeze-thaw cycles, the unconfined compressive strength tests were conducted using three groups of soil. Each soil group was divided into four specimens, and $0,1,3$, and 6 freeze-thaw cycles were applied to each group. The freezing temperatures of the three groups were $0^{\circ} \mathrm{C},-5^{\circ} \mathrm{C}$, and $-15^{\circ} \mathrm{C}$, which correspond to the different plant roots in the reinforced soil experimental group.

To ensure the reliability of the test results, each test was applied to three parallel specimens, and discrete points that did not fall within three times the standard deviation were eliminated. The average values of the tests were used as the results, and the test results with the smallest absolute value from the mean values of the reliable experimental data were used as the analysis data.

3.2. Pull-Out Test Method. To determine the mechanism of plant RR of clay soil, the interfacial shear stress must be measured to determine the forces acting between the fibers 


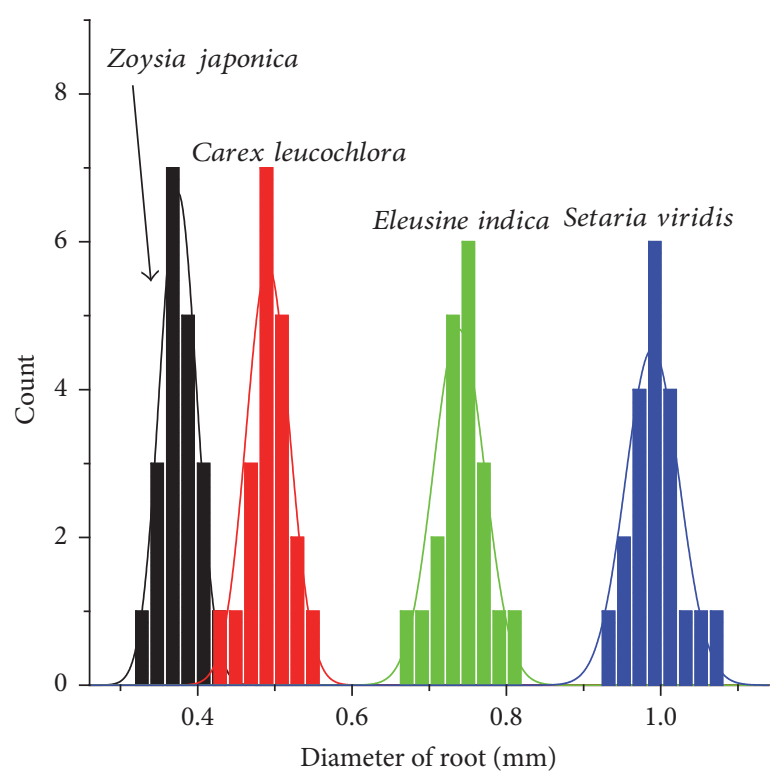

(a)

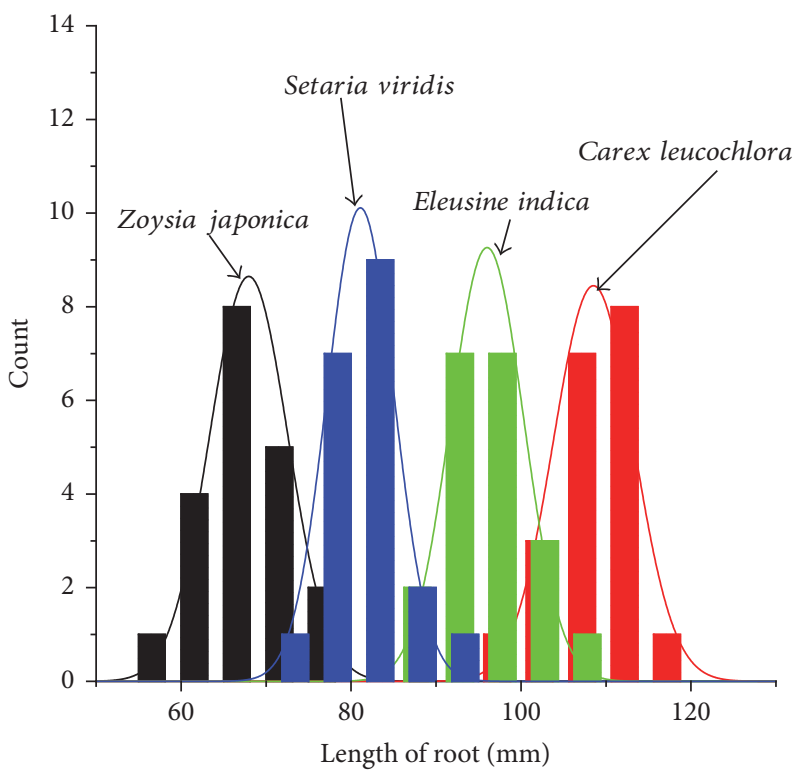

(b)

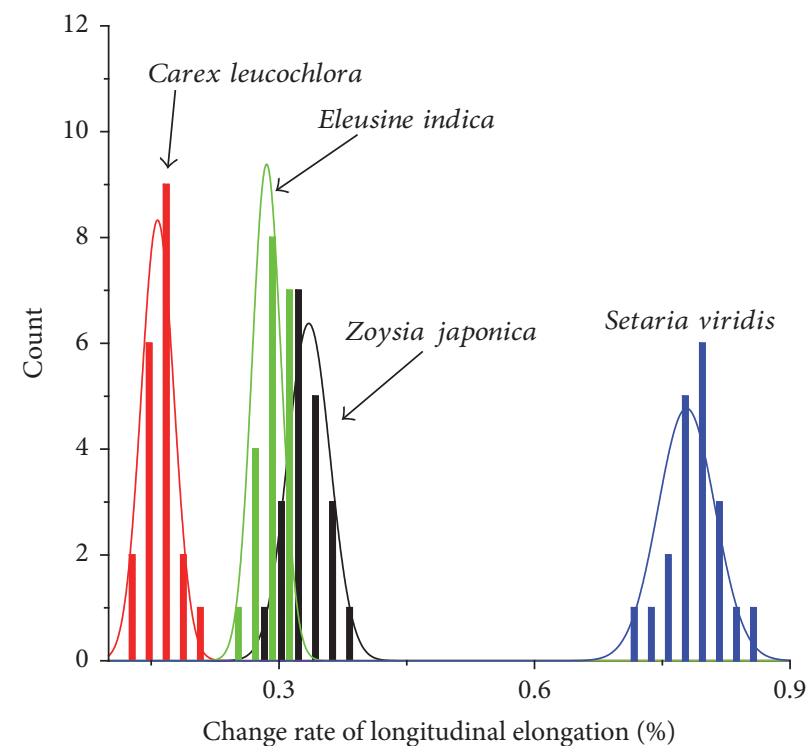

(c)

FIGURE 4: Charts of the basic parameters of the root system. (a) Diameter; (b) length; (c) change rate of longitudinal elongation.

and the matrix [17]. The interfacial friction force between the soil and the plant root and the changes in the reinforced soil friction during the pull-out process were measured during the pull-out experiments on single-root plants. A homemade experimental instrument was used to perform the pull-out experiments on reinforced soil and to control the pull-out rate. For the tests, the controlled pull-out rate was $0.16 \mathrm{~mm} / \mathrm{s}$, and a digital force gauge with a sensitivity of $0.01 \mathrm{~N}$ (ZP500, HK AIGU Instrument \& Apparatus Co. Ltd., China) was used to measure the pull-out force. The size of the soil specimens was the same as that of the direct shear specimens $(61.8 \times 20 \mathrm{~mm})$, and the experimental specimens were prepared using vibration compaction as follows. The plant roots selected from the field were washed and allowed to dry in natural wind. The roots with the best shape and diameters close to the average root diameter were chosen. Then, a $10 \mathrm{~cm}$ section was cut from the middle of the plant roots for spare samples. To achieve a $92 \%$ compaction degree, dry soil and sufficient water to achieve an $18 \%$ water content were weighed and uniformly mixed. After mixing, the soil was placed in a sealed vessel for 24 hours to evenly distribute the moisture content. A vibrating hammer was then used to compact the soil. Half of the total soil for a sample was placed into a sleeve, and the plant roots were distributed throughout the sleeve gap. To simulate pulling the roots of herbaceous plants out from soil during an actual engineering project, the thick end of the plant root was used as the anchorage end. At the end of the embedded section, $10 \mathrm{~mm}$ of the root was 
TABle 3: Pull-out test program.

\begin{tabular}{lccc}
\hline Test number & Root type & $\begin{array}{c}\text { Freezing } \\
\text { temperature }\end{array}$ & $\begin{array}{c}\text { Freeze-thaw } \\
\text { times }\end{array}$ \\
\hline 1 & Zoysia japonica & $0^{\circ} \mathrm{C}$ & 0 \\
2 & & 1 \\
3 & & 3 \\
4 & & $0^{\circ} \mathrm{C}$ & 6 \\
\hline 5 & Carex leucochlora & & 0 \\
6 & & & 3 \\
7 & & $-5^{\circ} \mathrm{C}$ & 6 \\
8 & & & 0 \\
\hline 9 & Eleusine indica & 3 \\
10 & & & 6 \\
11 & & & 0 \\
12 & & & 1 \\
\hline 13 & & & 3 \\
14 & & & 6 \\
15 & & & \\
16 & & & \\
\hline
\end{tabular}

exposed, $61.8 \mathrm{~mm}$ of the root was embedded in the soil, and $28.2 \mathrm{~mm}$ of the anchorage end was exposed. The second half of the soil was poured into the sleeve, and a cushion block was placed into the sleeve to compact the soil using the vibrating hammer. The molded specimens had a cylindrical shape with a diameter of $61.8 \mathrm{~mm}$ and a height of $40 \mathrm{~mm}$. The tensile strength of the plant root system from the pull-out tests was automatically recorded by the computer terminal, and the pull-out curves were generated from these measurements. The experimental operation is shown in Figure 5.

To investigate the interfacial friction between the plant roots and soil under varying freeze-thaw cycles, four different plant roots and soils were used to prepare specimens using the same degree of compaction and water content. After the samples were subjected to different freeze-thaw cycles, the pull-out tests were conducted. A DX-300-40 lowtemperature testing unit was used to conduct the freezethaw cycles; the freezing and thawing temperatures were controlled within $0.1^{\circ} \mathrm{C}$. According to the actual temperature conditions of the four different plants and considering the most unfavorable situation, $-15^{\circ} \mathrm{C}$ and $5^{\circ} \mathrm{C}$ were used as the freezing temperatures for Setaria viridis and Eleusine indica, respectively, and $0^{\circ} \mathrm{C}$ was used for Zoysia japonica and Carex leucochlora. Room temperature was used as the thawing temperature, and the freezing and thawing cycles lasted for 24 hours (the freezing and thawing periods lasted for 12 hours each). During the freeze-thaw cycles, the specimens were wrapped with multiple layers of plastic wrap to prevent water loss.

3.3. Scheme of the Unconfined Compressive Strength Tests. The unconfined compressive strengths of the specimens were tested after different numbers of freeze-thaw cycles. The cylindrical specimens had a height of $80 \mathrm{~mm}$ and a diameter of $38.1 \mathrm{~mm}$. The specimen preparation method was consistent with that of the pull-out specimens, and the root content was consistent with the actual root density obtained from the corresponding geographical location. Considering the effect of the size of the root, the plant roots were cut to $20 \mathrm{~mm}$, and the soil samples were prepared according to a $92 \%$ compaction degree and $18 \%$ water content. The samples were thoroughly mixed with the plant roots and then pressed using the two-way static pressure method. The freeze-thaw process of the specimens was consistently maintained throughout the pull-out tests.

After the freeze-thaw cycles, unconfined compressive strength tests were conducted. Unconfined vertical loading tests were performed using a universal testing machine (WDW-100 computer-controlled electronic universal tester, Changchun KeXin Experimental Instrument Co. Ltd., China). The loading mode of the testing machine involved a stepless speed change, and the loading rate was controlled at $5 \mathrm{~mm} / \mathrm{min}$. The precision of the displacement sensor was $0.01 \mathrm{~mm}$, the precision of the force sensor was $0.5 \mathrm{~N}$, and the computer connected to the universal testing machine automatically collected and stored the stress-strain curves of the specimens during testing. After extracting the stressstrain curve peaks, the unconfined compressive strengths of the specimens were determined. The loading scheme for the unconfined compressive strength tests is shown in Figure 6.

\section{Results and Analysis of the Experiments}

4.1. Pull-Out Experiments. The pull-out tests of the single roots were performed according to Table 3 , and the pull-out process curves for the different plant roots under freeze-thaw conditions are shown in Figures 7(a), 7(b), 7(c), and 7(d).

According to Figure 7, the curve of the interfacial friction force between the plant roots and the soil was divided into four stages using different freezing and thawing times. In conjunction with a relevant study [18], the four stages of the force state can be expressed using

$$
\begin{aligned}
& F(x) \\
& = \begin{cases}E \cdot u(x), & \left(0<u<u_{1}\right), \\
F_{\max }+\frac{F_{\max }-F_{\mathrm{res}}}{u_{1}-u_{2}}\left(u(x)-u_{1}\right), & \left(u_{1}<u<u_{2}\right), \\
F_{\text {res }}+\frac{F_{\mathrm{res}}}{u_{2}-u_{3}}\left(u(x)-u_{2}\right), & \left(u_{2}<u<u_{3}\right), \\
0, & \left(u_{3}<u<u_{4}\right) .\end{cases}
\end{aligned}
$$

The first stage was the elastic stage. During this stage, the root tendons of the plant were deformed under tension, and the friction between the root tendons and the soil block gradually increased. The interfacial friction force $f$ was equal to the tension force of the root and increased with increasing traction force of the root outside the soil. When the external tension exceeded the maximum static friction between the root and the soil, the pull-out test entered the second stage. During this stage, the root was pulled out, and the soil particles that were in contact with the plant roots moved; hence, the interface friction decreased rapidly. As the plant 


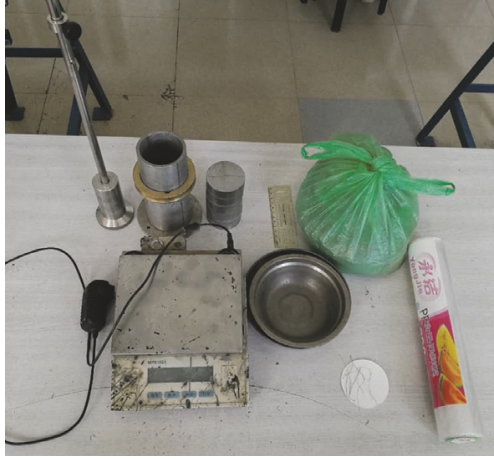

Test material preparation

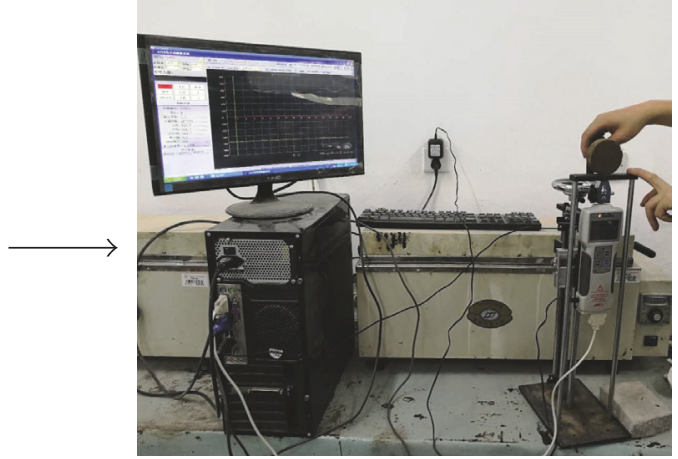

Digital force gauge

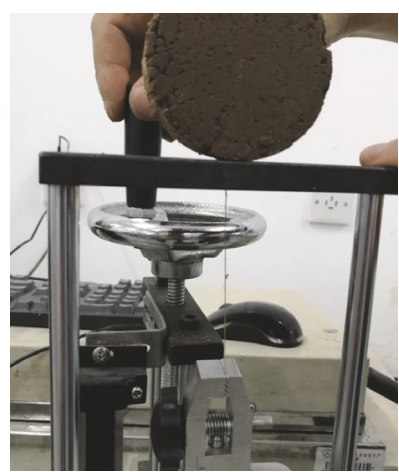

Root drawing

FIgURE 5: Material preparation and operating process of the pull-out experiment.

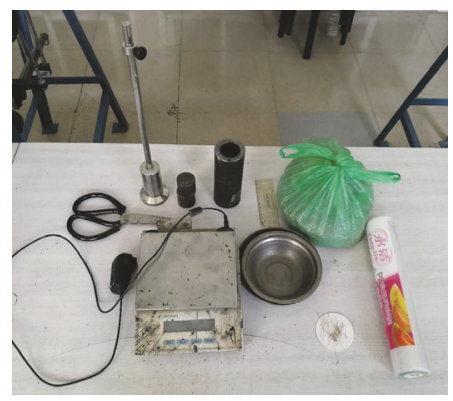

Test material preparation

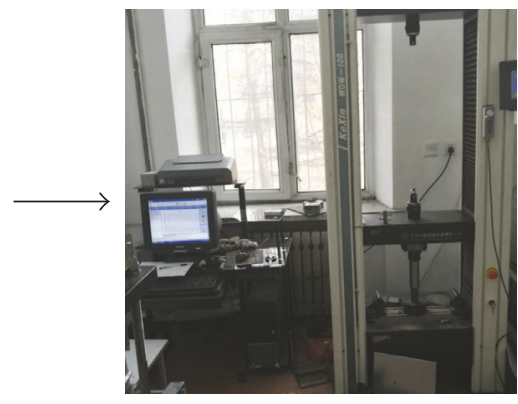

Universal testing machine

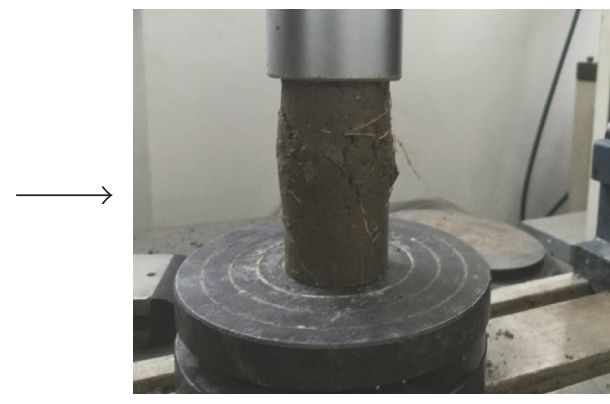

Breaking test-piece

FIGURE 6: Loading scheme of the unconfined compressive strength tests.

roots were gradually pulled out, the internal soil particles rearranged to form a new friction interface. At this point, the curve of the interfacial friction between the root and the soil showed an inflection point, and the corresponding value of this point was recorded as the residual shear force between the root and the soil. During the third stage, the length of the root anchor in the soil decreased, so the value of the interface friction did not remain constant and eventually reached zero. During the fourth stage, the interfacial friction force between the root and the soil was zero because the diameter of the back end of the root decreased while the front section became thicker. Although the root was not completely pulled out, there was no effective contact between the soil particles and the root of the plant. Equation (2) was used to fit the experimental data curve, and the trends of the four stages are shown in Figure 8.

Since the first stage could be approximated as a pure elastic phase, the elastic moduli of the different plant roots were deduced using a physical equation (4) and geometric deformation equation (5) for single-root tension during the pull-out tests; the moduli are provided in Table 4.

$$
\begin{aligned}
& \varepsilon=\frac{\sigma}{E}=\frac{F}{\pi E r^{2}}, \\
& \varepsilon=\frac{\Delta l}{l},
\end{aligned}
$$

TABLE 4: Elastic moduli (E) (MPa).

\begin{tabular}{lcccc}
\hline \multirow{2}{*}{ Plant roots } & \multicolumn{4}{c}{ Freeze-thaw times } \\
& $0 \mathrm{~d}$ & $1 \mathrm{~d}$ & $3 \mathrm{~d}$ & $6 \mathrm{~d}$ \\
\hline Carex leucochlora & 30.46 & 62.44 & 58.21 & 36.15 \\
Zoysia japonica & 762.71 & 945.53 & 1015.69 & 821.88 \\
Setaria viridis & 54.51 & 60.52 & 63.16 & 45.19 \\
Eleusine indica & 530.52 & 361.72 & 410.45 & 318.30 \\
\hline
\end{tabular}

where $F$ is the pull-out force of the root, $r$ is the mean radius of the root, $\Delta l$ is the tensile deformation of the root, and $l$ is the total length of the root.

According to Table 4, Young's moduli of different plant roots differ greatly, and the elastic moduli of the four kinds of plant roots have the following order: Zoysia japonica > Eleusine indica $>$ Setaria viridis $>$ Carex leucochlora. Thus, Zoysia japonica exhibited the best resistance to elastic tensile deformation. Young's modulus is shown to be significantly affected by the freeze-thaw cycle, showing a trend of first increasing and then decreasing.

The peak points $\left(F_{\max }\right)$ were extracted from the experimental curves of the root and soil complexes of the plants, and the maximum shear strength trends of the root-soil interface under different freeze-thaw cycle times are shown in Figure 9.

According to Figure 9, the interfacial friction effect between Zoysia japonica and the soil was most significant, 

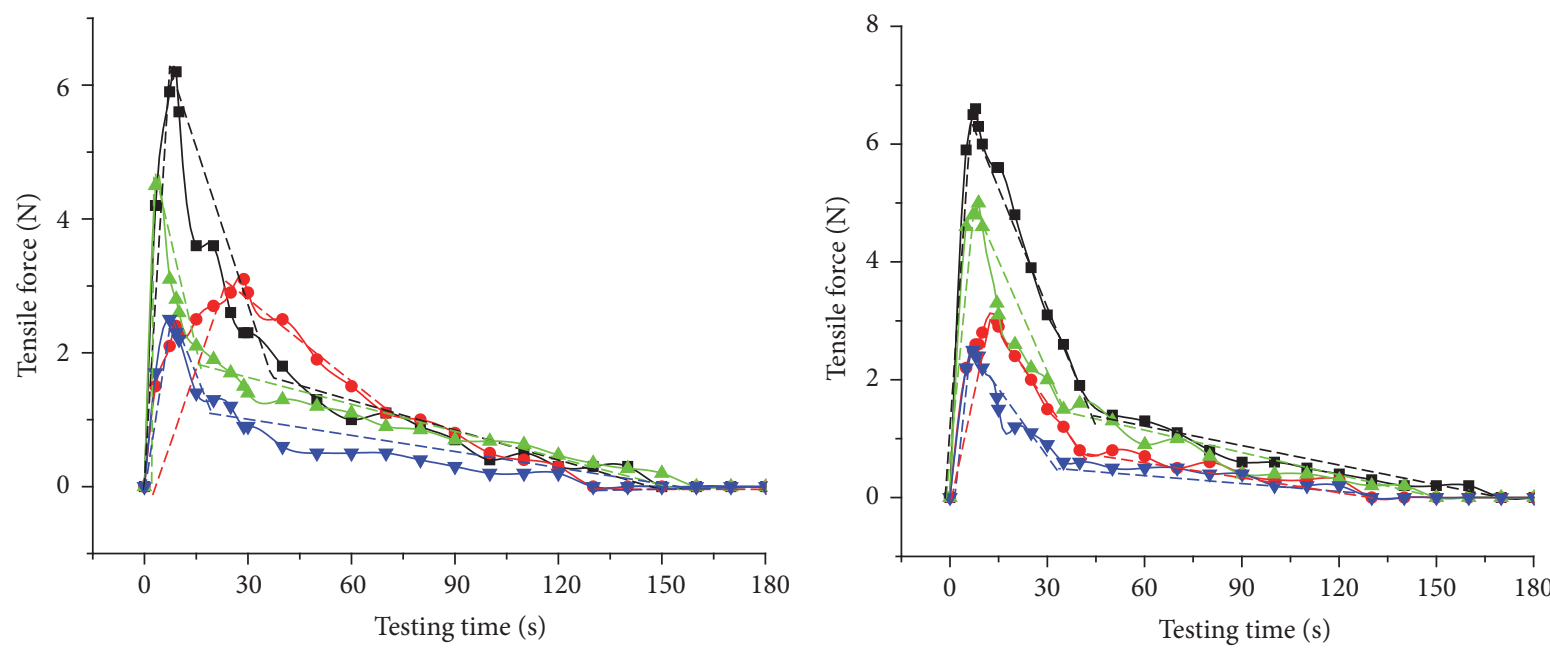

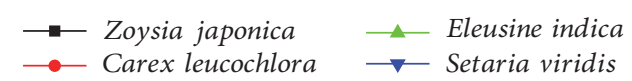

(a)

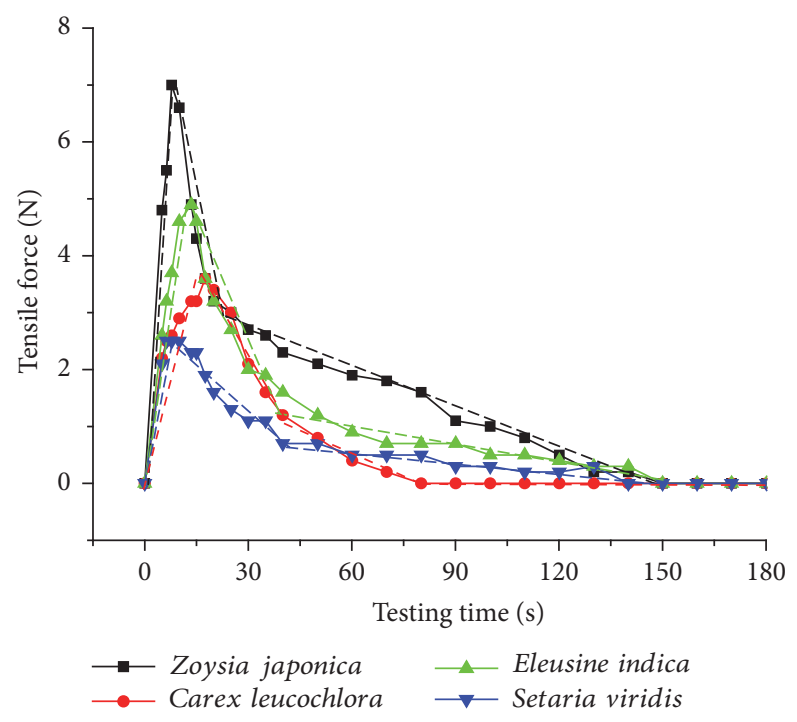

(c)

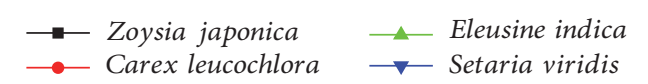

(b)

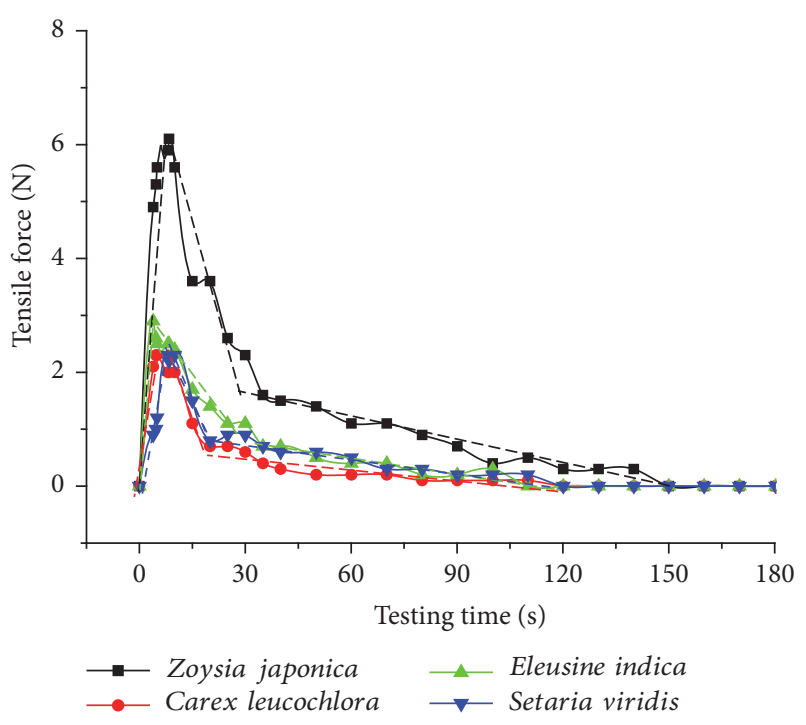

(d)

FIGURE 7: Pull-out process curves of the different plant roots under freeze-thaw conditions. (a) 0 days; (b) 1 day; (c) 3 days; (d) 6 days.

followed by those of Eleusine indica, Carex leucochlora, and Setaria viridis. In accordance with the study by Tang et al. [19], the strength of the contact surface between the plant root and the soil was mainly composed of two parts: interfacial adhesion and interfacial friction. The degree of interfacial adhesion was mainly affected by the clay content and the natural binding material.

The interfacial friction force was mainly related to the soil, water content, positive pressure, surface roughness of the plant root, and the effective contact area between the soil and the root. Since the initial state of the soil was the same value for each experiment, the friction force between the soil and the roots was mainly related to the surface roughness of the plant roots and the contact area between the soil and the roots. Therefore, the maximum static friction between the soil during the pull-out tests was expressed as shown in (6).
Microscopic images of the surfaces of the four plant roots under a digital microscope are shown in Figure 10.

$$
F=2 \mu \pi \bar{r} l \cdot \bar{N} \text {. }
$$

In the above equation, $F$ is the interface friction, and $\mu$ is the interface friction coefficient, which is mainly related to the root surface roughness and soil moisture content.

$\bar{N}$ is the mean positive pressure of the soil particles on the root, which is mainly related to the porosity of the soil and the external load, and $\bar{r}$ is the mean diameter of the roots.

According to Figure 10, although the Zoysia japonica roots had a small diameter, they had a rough surface, and the interface friction coefficient between the roots and soil particles was large. Therefore, this root exhibited good pullout resistance. In combination with (6), the diameters of the four kinds of plant roots increased in the following order: 


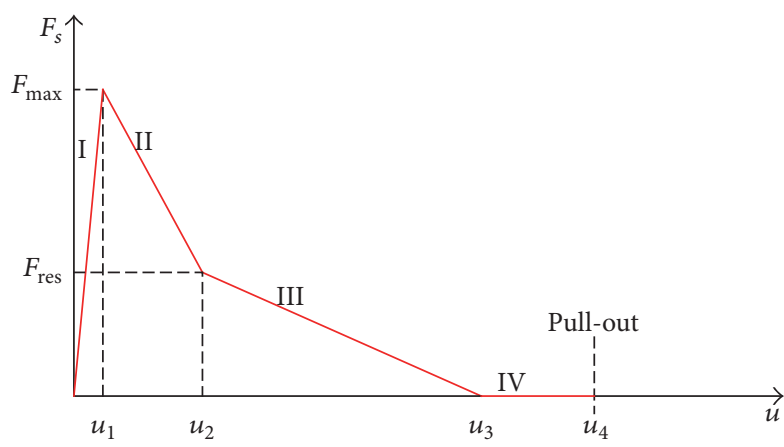

FIGURE 8: Four stages of the pull-out tests.

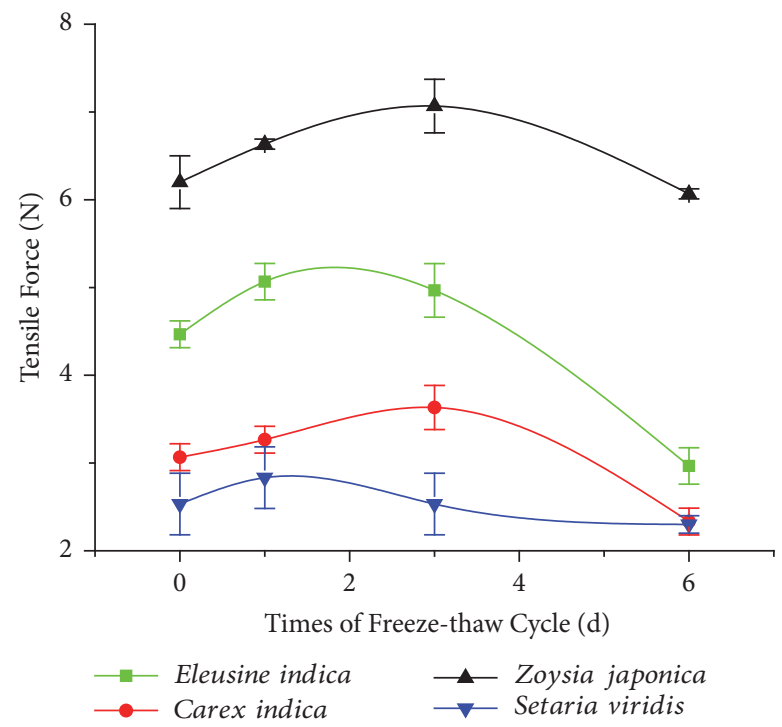

FIGURE 9: Maximum shear strength trends of the root-soil interface after varying freeze-thaw cycle times.

Zoysia japonica < Eleusine indica < Carex leucochlora < Setaria viridis. However, their pull-out resistance followed the exact opposite order. These two factors have opposite effects on the interfacial friction effect, but the trend of root tension is consistent with that of the root surface friction coefficient. The differences between the friction coefficients of the plant surfaces were large, and the surface roughness of the plant roots was the most important factor for soil reinforcement.

In addition, the interfacial shear strength of the four different roots first increased and then decreased with increasing freeze-thaw cycles. The interfacial shear strength of Setaria viridis exhibited a peak value after one freezethaw cycle, while the roots of the other three plants exhibited peak values after three freeze-thaw cycles. Although the interfacial shear strength of Setaria viridis was small, the shear strength exhibited a slow decreasing trend with an increasing number of freeze-thaw cycles. After six freeze-thaw cycles, the interfacial shear strength decreased by $8 \%$, indicating that Setaria viridis has good antifreeze properties.

During the freeze-thaw cycles, the soil particles were broken, as shown in Figure 11 [20]. With an increasing number of freeze-thaw cycles, the soil particles were increasingly broken. Then, the soil particles continued to be broken, but the crushing effect gradually weakened. Therefore, when the number of freeze-thaw cycles was small, the contact area between the soil and the plant root increased due to the fragmentation of the soil particles, which increased the contact area between the plant roots and the soil. Therefore, the interfacial shear strength between the plant root and the soil increased; however, after many freeze-thaw cycles, the interfacial cohesion of the soil significantly decreased, which in turn significantly decreased the soil cohesion. After that point, the fragmentation of the small soil particles after freeze-thaw cycles was not obvious, which reduced the interfacial shear strength between the soil particles and plant roots.

4.2. Unconfined Compressive Strength Tests. Unconfined compressive strength tests were conducted according to the experimental design, and the stress-strain curves of the reinforced soil using the four kinds of plant roots were measured during different freeze-thaw cycles, as shown in Figures 12(a), 12(b), 12(c), and 12(d).

As shown in Figure 12, when the soil was mixed with the plant roots, its unconfined strength was higher than that of the soil without plant roots. In the diagram, the stress-strain relationship exhibited a linear change when the strain values were small, indicating that the specimens of the reinforcement soil were still in the elastic phase. When the soil reached the extreme stress value, that is, the unconfined compressive strength, it immediately yielded, and its stress decreased significantly, similar to the soil reinforcement results using the root of Carex leucochlora. After soils reinforced with the other three kinds of plant roots were destroyed, the strength curve decreased slightly. The results showed that residual strength remained after the reinforced soils were destroyed, which improved the toughness of the soil, and related studies have also proved that fiber-reinforced materials exhibit ductile behavior after reaching their compressive strength [21]. When the soil is subjected to slight dislocation or tensile fracture, the root-soil composite system plays a certain role in reinforcing the soil. The soil in the root-soil composite system showed that the soil displacement stopped when the effect of the root system on the soil reinforcement had not completely disappeared; in a stable level, in which the soil is immobilized, the large deformation resistance of the soil is of great significance. With an increasing number of freeze-thaw cycles, the stress-strain curves of the reinforced soils began to exhibit significant attenuation after reaching the unconfined compressive strength. The results show that an increasing number of freeze-thaw cycles improved the soil toughness.

According to the results in Figure 12, the unconfined compressive strength of each experimental group was extracted and subtracted from that of the soil to obtain the unconfined compressive strength increment at the corresponding temperature. Figures $13(\mathrm{a})$ and 13(b) present the analysis of the reinforcement effects of the plant roots and the trends of the unconfined compressive strength increment of the plant roots under varying numbers of freeze-thaw cycles. 


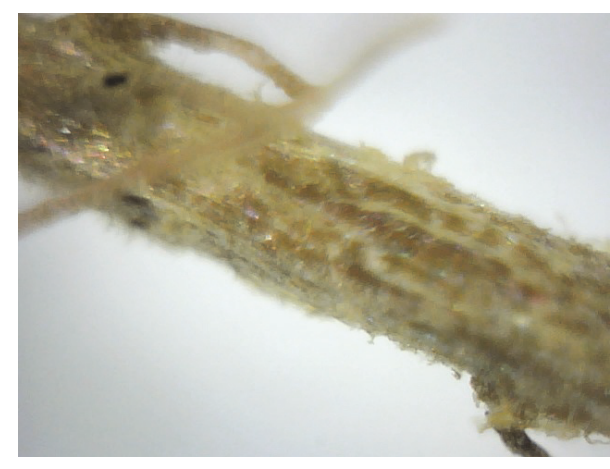

(a) Eleusine indica

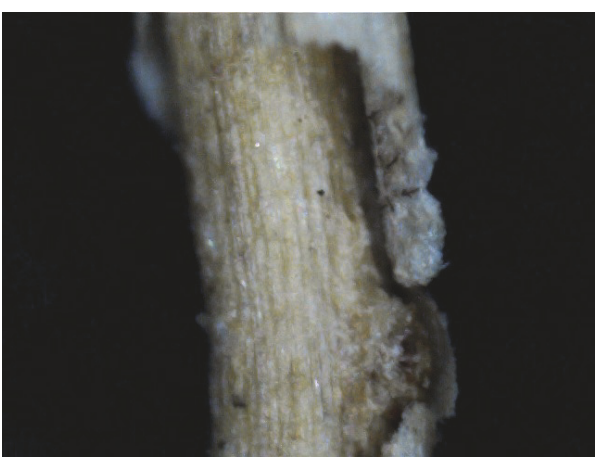

(c) Zoysia japonica

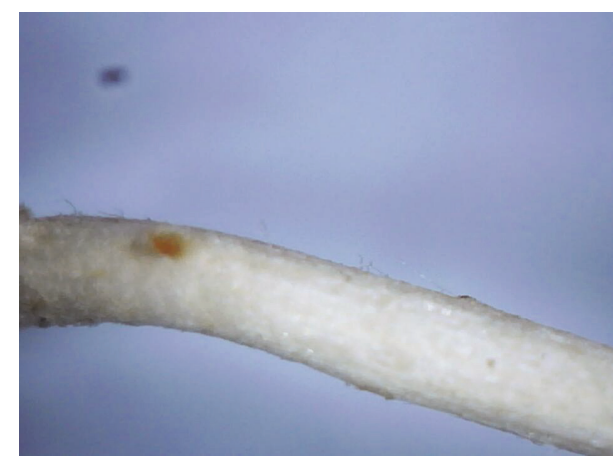

(b) Carex leucochlora

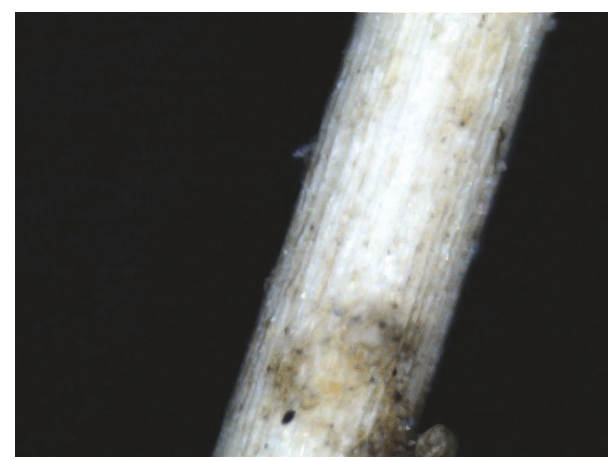

(d) Setaria viridis

Figure 10: Microscopic images of the surfaces of the four plant roots under a digital microscope.

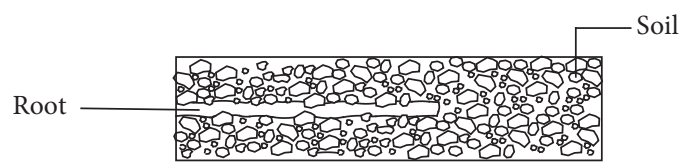

(a)

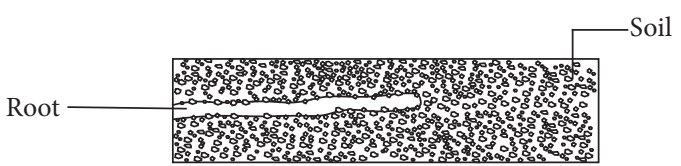

(b)

FIGURE 11: Variation in the soil-root interface after freeze-thaw cycles. (a) Before the freeze-thaw cycles. (b) After the freeze-thaw cycles.

As shown in Figure 13, the unconfined compressive strength of the root of Zoysia japonica was the largest for the same number of freeze-thaw cycles; at a 59.14\% increase, this root showed the best reinforcement effect. The unconfined compressive strength of the root system using Setaria viridis was the smallest, and its increment was $41.33 \%$, indicating that its effect on soil reinforcement was not significant. With an increasing number of freeze-thaw cycles, the increment of the unconfined compressive strength of the reinforced soils first increased and then decreased. This finding was consistent with the shear strength trends of the interface of the reinforced soil under freeze-thaw conditions during pullout tests.

Because Zoysia japonica exhibited the best reinforcement effect, the destruction patterns of the reinforced soil and pure soil were compared under different numbers of freeze-thaw cycles, as shown in Figure 14.

As shown in Figure 14, the soil destruction process in the presence of plant roots was significantly better than that of the soil without roots. During the compression process, the surface of the soil expanded, cracked, and shifted, and the specimens containing the roots of Zoysia japonica became inflated. However, cracking of the reinforced specimens occurred at a later time without soil fragmentation. The soil damage for both specimens became more severe with an increasing number of freeze-thaw cycles, but the soils with plant roots were less affected by the freeze-thaw cycles.

The interfacial friction effect between the soil and the soil particles and the spatial mesh effect of the intertwined root system were the main contributors for the soil reinforcement (Figure 15).

Thus, the unconfined compressive strength increment could be added to two parts. The first part was caused by the interfacial friction effect between the plant roots and the soil particles at the rupture zone. This contribution to the incremental increase was directly related to the shear strength of the interface during the pull-out tests. The second part was the strength reinforcement provided by the plant roots that were not in the crushing zone due to the spatial mesh effect. To investigate the spatial mesh effect using different 


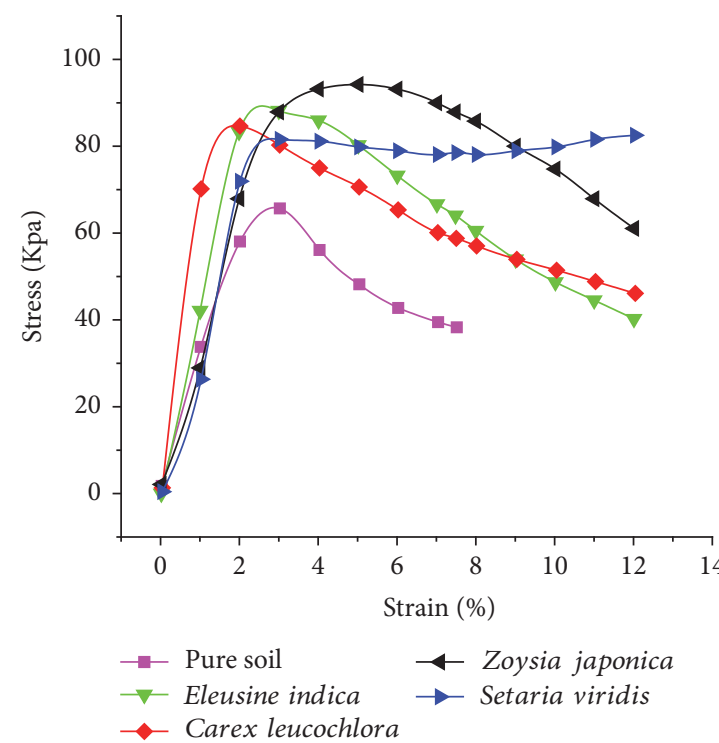

(a)

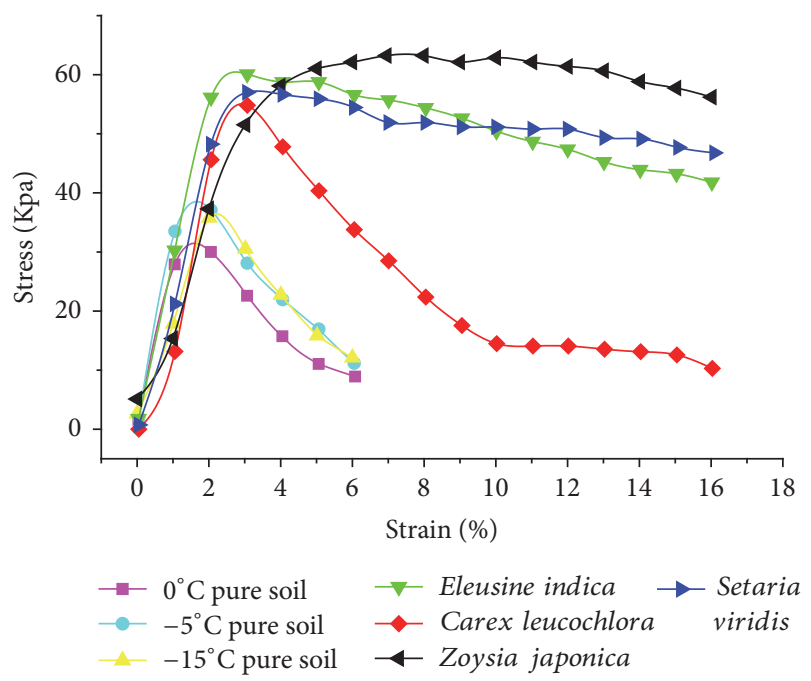

(c)

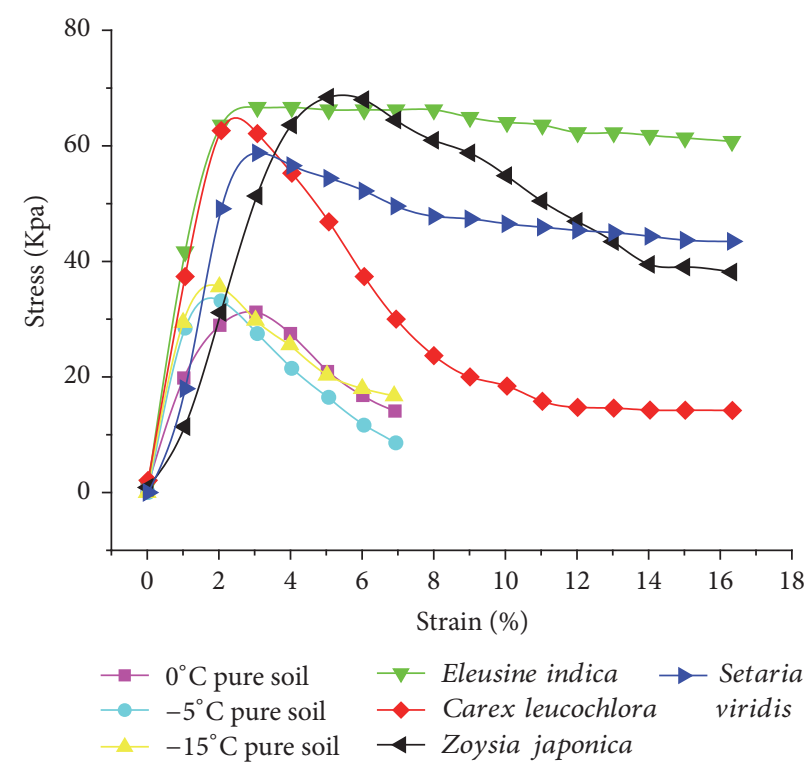

(b)

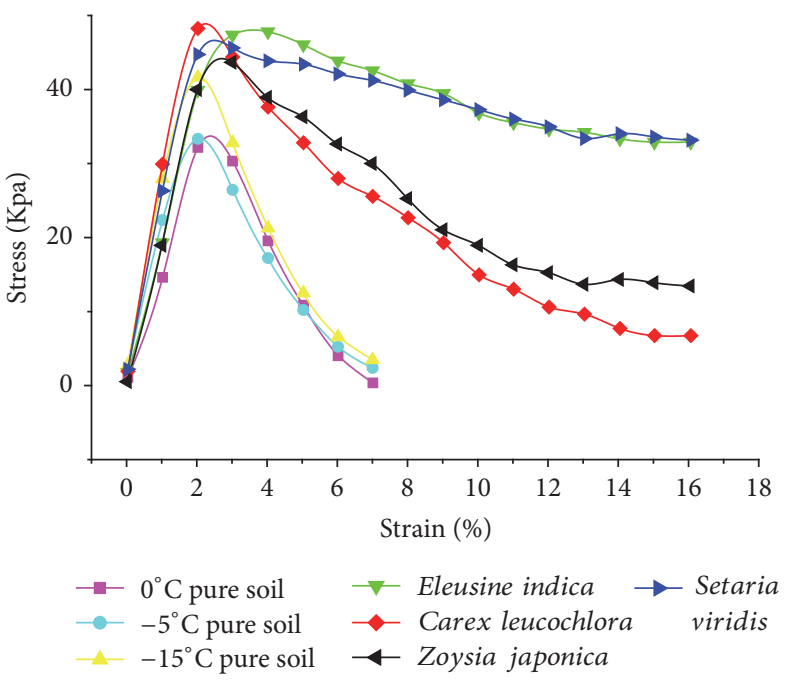

(d)

FIGURE 12: Stress-strain curves of specimens after varying freeze-thaw cycle times. (a) 0 days; (b) 1 day; (c) 3 days; (d) 6 days.

plant roots under freeze-thaw conditions, it was assumed that the plant roots were completely and evenly distributed in the specimen. Using Eleusine indica as a benchmark, the following equation was used:

$$
\Delta q_{u}=\Delta q_{u}^{\prime}+\Delta q_{u}^{\prime \prime}
$$

where $\Delta q_{u}$ is the total increment in the unconfined compressive strength, $\Delta q_{u}^{\prime}$ is the direct increase in the unconfined compressive strength caused by the interfacial friction effect, and $\Delta q_{u}^{\prime \prime}$ is the indirect increase in the unconfined compressive strength caused by the spatial reticular effect.
For the two systems of roots $a$ and $b$,

$$
\begin{aligned}
\Delta q_{u a} & =\Delta q_{u a}^{\prime}\left(1+\frac{\Delta q_{u a}^{\prime \prime}}{\Delta q_{u a}^{\prime}}\right), \\
\Delta q_{u b} & =\Delta q_{u b}^{\prime}\left(1+\frac{\Delta q_{u b}^{\prime \prime}}{\Delta q_{u b}^{\prime}}\right), \\
\alpha_{a} & =\frac{\Delta q_{u a}^{\prime \prime}}{\Delta q_{u a}^{\prime}}, \\
\alpha_{b} & =\frac{\Delta q_{u b}^{\prime \prime}}{\Delta q_{u b}^{\prime}},
\end{aligned}
$$




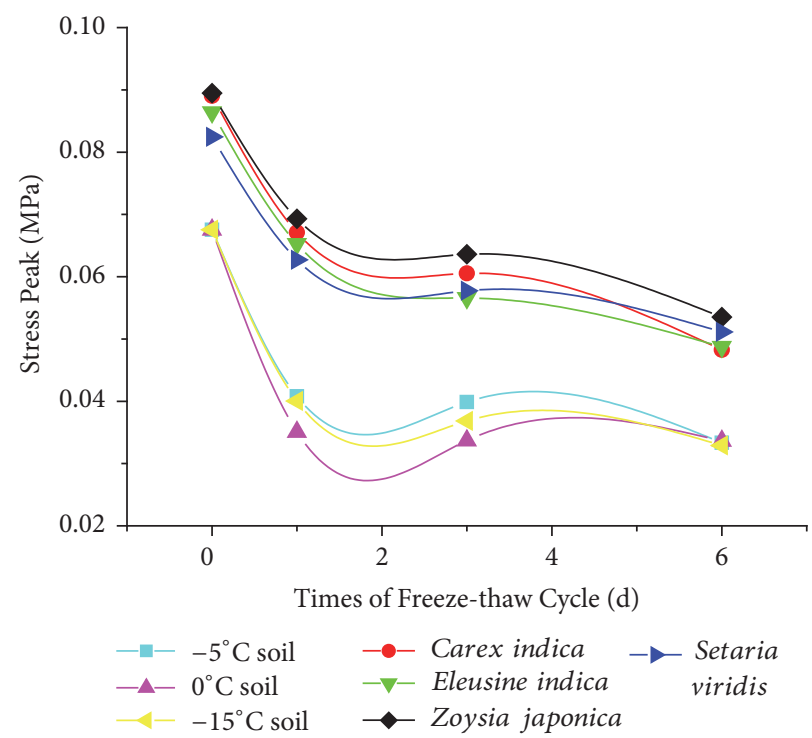

(a)

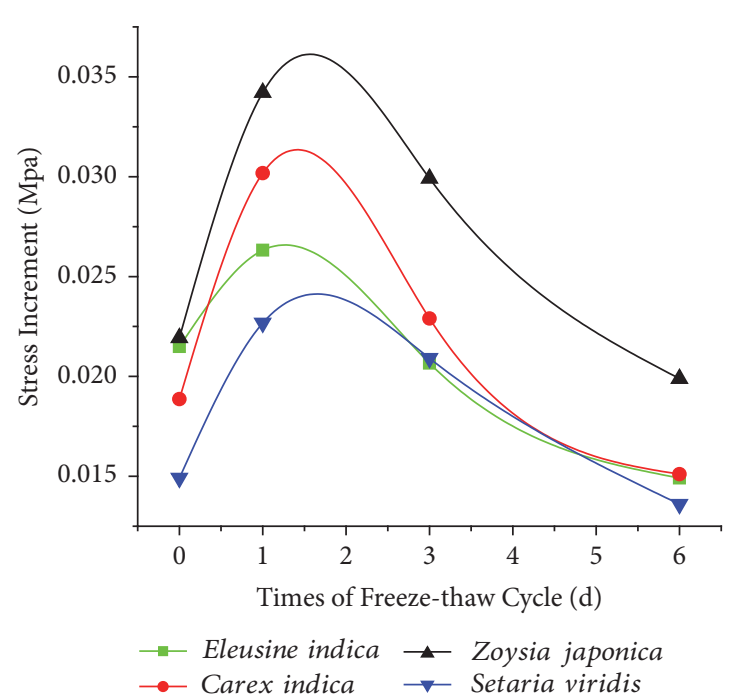

(b)

FIGURE 13: Trends of the unconfined compressive strength under varying numbers of freeze-thaw cycles. (a) Unconfined compressive strength; (b) unconfined compressive strength increment.

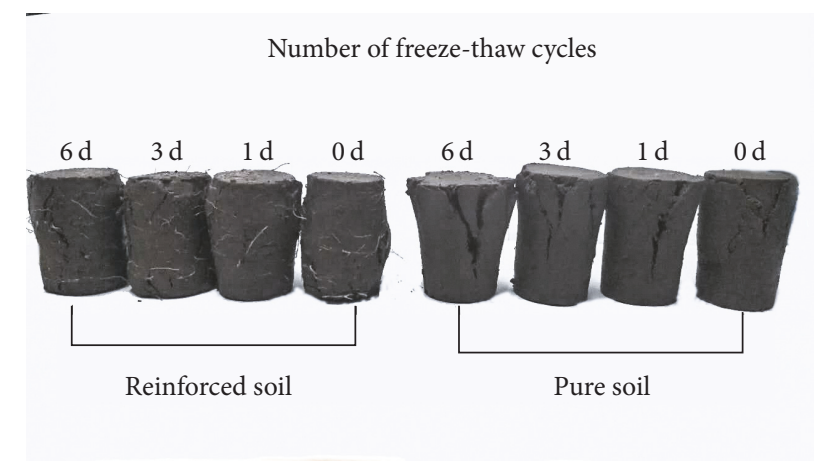

FIGURE 14: Destruction patterns of the reinforced soil and pure soil under different numbers of freeze-thaw cycles.

where $\alpha$ is the indirect incremental contribution coefficient, which represents the ratio of the intensity increment caused by the fixed space network effect.

Setting

$$
\beta=\frac{\Delta q_{u a} \Delta q_{u b}^{\prime}}{\Delta q_{u b} \Delta q_{u a}^{\prime}}=\frac{1+\alpha_{a}}{1+\alpha_{b}},
$$

if $\beta>1$, then $\alpha_{a}>\alpha_{b}$; that is, the indirect contribution of $a$ species of plants becomes greater.

Therefore,

$$
\frac{\Delta q_{u b}^{\prime}}{\Delta q_{u a}^{\prime}}=\frac{f_{2} r_{1}{ }^{2} S_{2}}{f_{1} r_{2}^{2} S_{1}} .
$$

Thus, the spatial effects of the different root systems can be directly compared. As $\beta$ increases, the spatial effect of the roots of Eleusine indica becomes weaker. The $\beta$ values of the plant roots were calculated and are presented in Table 5 .

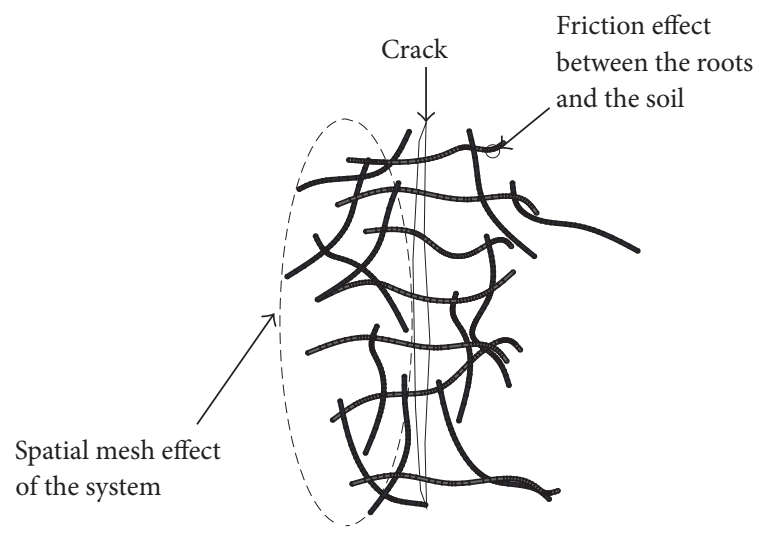

FIGURE 15: Reinforcement mechanism diagram.

According to Table 5, the $\beta$ value of Zoysia japonica was greater than 1, while the $\beta$ values of the other two plant roots were $<1$. These results indicate that the reinforcement effect of Zoysia japonica due to the spatial effect was the greatest.

\section{Conclusions}

Based on pull-out tests and unconfined compressive strength tests, the influences of different numbers of freeze-thaw cycles and different plant roots on the interfacial shear strength and unconfined compressive strength of soil were studied. The strengthening mechanisms of the plant roots in the soil were discussed, and the following conclusions were obtained:

(1) The single fiber pull-out tests effectively measured the interface friction between the plant root and clay. This information provides an important basis for 
TABLE 5: $\beta$ values.

\begin{tabular}{lcccc}
\hline & $0 \mathrm{~d}$ & $1 \mathrm{~d}$ & $3 \mathrm{~d}$ & \\
\hline$\beta_{0}$ & 1 & 1 & 1 & 1 \\
$\beta_{1}$ & 0.401 & 0.285 & 0.339 & 0.400 \\
$\beta_{2}$ & 5.521 & 4.152 & 4.034 & 6.450 \\
$\beta_{3}$ & 0.170 & 0.133 & 0.107 & 0.185 \\
\hline
\end{tabular}

Note. $\beta_{0}$ represents the indirect contribution of the roots of Eleusine indica compared with itself; $\beta_{1}$ represents the indirect contribution of the roots of Carex leucochlora compared with the indirect contribution of the roots of Eleusine indica; $\beta_{2}$ represents the indirect contribution of the roots of Zoysia japonica compared with the indirect contribution of the roots of Eleusine indica; $\beta_{3}$ represents the indirect contribution of the roots of Setaria viridis compared with the indirect contribution of the roots of Eleusine indica.

further analysis of the mechanical mechanism and the interface action of a reinforced root system.

(2) The pull-out process of the root system was divided into four stages: the elastic stage, the dynamic friction stage, the residual strength stage, and the resting stage. The interfacial shear strength of soil appears at the critical position between the first stage and the second stage.

(3) The strength and toughness of the soil were significantly improved by plant roots. Among the four plant roots, Zoysia japonica showed the most significant reinforcement effect and the largest increase in strength of $59.14 \%$.

(4) The soil reinforcement effect was mainly due to the friction effect between the roots and the soil and the spatial mesh effect of the root system. Among these effects, the interfacial shear friction effect between the roots of Zoysia japonica and the spatial reinforcement effect of the roots of Eleusine indica were the most significant. In addition, the peak displacement and softening section length of the root-soil system were enhanced, and the soil ductility was improved.

(5) The effect of the number of freeze-thaw cycles on the plant reinforcement was very significant. With an increasing number of freeze-thaw cycles, Zoysia japonica has the most obvious enhancement effect, while Setaria viridis has the highest frost resistance. The interface shear strength and unconfined compressive strength between the various plant roots and the soil first increased and then decreased with increasing freeze-thaw cycles.

\section{Conflicts of Interest}

The authors declare that they have no conflicts of interest.

\section{Authors' Contributions}

Yulong He and Lin Yang developed and designed the experiments; Hengxing Wang and Hong Guo performed the experiments; Hengxing Wang and Yulong He analyzed the data; Lin Yang and Chunpeng Han contributed the instruments, materials, and analysis tools; Yulong He and Hengxing Wang wrote the paper; and Yafeng Gong edited and audited the content.

\section{Acknowledgments}

This work was supported by the Science and Technology Project of Heilongjiang Provincial Department of Transport, Fundamental Research Funds for the Central Universities [2572014CB21], and Natural Science Foundation of Heilongjiang Province in China [E201349].

\section{References}

[1] S. B. Mickovski, P. D. Hallett, M. F. Bransby, M. C. R. Davies, R. Sonnenberg, and Bengough A. G., "Mechanical reinforcement of soil by willow roots: Impacts of root properties and root failure mechanism," Soil Science Society of America Journal, vol. 73, no. 4, pp. 1276-1285, 2009.

[2] K. W. Loades, A. G. Bengough, M. F. Bransby, and P. D. Hallett, "Planting density influence on fibrous root reinforcement of soils," Ecological Engineering, vol. 36, no. 3, pp. 276-284, 2010.

[3] G. Veylon, M. Ghestem, A. Stokes, and A. Bernard, "Quantification of mechanical and hydric components of soil reinforcement by plant roots," Canadian Geotechnical Journal, vol. 52, no. 11, pp. 1839-1849, 2015.

[4] M. Bordoni, C. Meisina, A. Vercesi et al., "Quantifying the contribution of grapevine roots to soil mechanical reinforcement in an area susceptible to shallow landslides," Soil and Tillage Research, vol. 163, pp. 195-206, 2016.

[5] M. Burylo, C. Hudek, and F. Rey, "Soil reinforcement by the roots of six dominant species on eroded mountainous marly slopes (Southern Alps, France)," Catena, vol. 84, no. 1-2, pp. 7078, 2011.

[6] P. Voottipruex, D. T. Bergado, W. Mairaeng, S. Chucheepsakul, and C. Modmoltin, "Soil reinforcement with combination roots system: A case study of vetiver grass and Acacia Mangium Willd," Lowland Technology International, vol. 10, no. 2, pp. 5667, 2008.

[7] M. Saifuddin and N. Osman, "Evaluation of hydro-mechanical properties and root architecture of plants for soil reinforcement," Current Science, vol. 107, no. 5, pp. 845-852, 2014.

[8] L. J. Waldron and S. Dakessian, "Soil reinforcement by roots: Calculation of increased soil shear resistance from root properties," Soil Science, vol. 132, no. 6, pp. 427-435, 1981.

[9] T. H. Wu, W. P. McKinnell III, and D. N. Swanston, "Strength of tree roots and landslides on Prince of Wales Island, Alaska," Canadian Geotechnical Journal, vol. 16, no. 1, pp. 19-33, 1979.

[10] F. Bourrier, F. Kneib, B. Chareyre, and T. Fourcaud, "Discrete modeling of granular soils reinforcement by plant roots," Ecological Engineering, vol. 61, no. 1, pp. 646-657, 2013. 
[11] D. Kim, S. Ho Lee, E. A. Combalicer, Y. Hong, and S. Im, "Estimating soil reinforcement by tree roots using the perpendicular root reinforcement model," International Journal of Erosion Control Engineering, vol. 3, no. 1, pp. 80-84, 2010.

[12] Z. Mao, Y. Ming, F. Bourrier, and T. Fourcaud, "Evaluation of root reinforcement models using numerical modelling approaches," Plant and Soil, vol. 381, no. 1-2, pp. 249-270, 2014.

[13] B. B. Docker and T. C. T. Hubble, "Quantifying rootreinforcement of river bank soils by four Australian tree species," Geomorphology, vol. 100, no. 3-4, pp. 401-418, 2008.

[14] T. H. Wu, "Root reinforcement of soil: Review of analytical models, test results, and applications to design," Canadian Geotechnical Journal, vol. 50, no. 3, pp. 259-274, 2013.

[15] M. Schwarz, A. Rist, D. Cohen et al., "Root reinforcement of soils under compression," Journal of Geophysical Research F: Earth Surface, vol. 120, no. 10, pp. 2103-2120, 2015.

[16] T. C. Hales and C. F. Miniat, "Soil moisture causes dynamic adjustments to root reinforcement that reduce slope stability," Earth Surface Processes and Landforms, vol. 42, no. 5, pp. 803813, 2017.

[17] C. Santulli, "Impact properties of glass/plant fibre hybrid laminates," Journal of Materials Science, vol. 42, no. 11, pp. 36993707, 2007.

[18] C. Tang, B. Shi, W. Gao, F. Chen, and Y. Cai, "Strength and mechanical behavior of short polypropylene fiber reinforced and cement stabilized clayey soil," Geotextiles and Geomembranes, vol. 25, no. 3, pp. 194-202, 2007.

[19] C.-S. Tang, X.-J. Pei, D.-Y. Wang, B. Shi, and J. Li, "Tensile strength of compacted clayey soil," Journal of Geotechnical and Geoenvironmental Engineering, vol. 141, no. 4, Article ID 04014122, 2015.

[20] C. Han and P. Cheng, "Micropore variation and particle fractal representation of lime-stabilised subgrade soil under freeze-thaw cycles," Road Materials and Pavement Design, vol. 16, no. 1, pp. 19-30, 2015.

[21] S.-C. Lee, J.-H. Oh, and J.-Y. Cho, "Compressive behavior of fiber-reinforced concrete with end-hooked steel fibers," Materials, vol. 8, no. 4, pp. 1442-1458, 2015. 

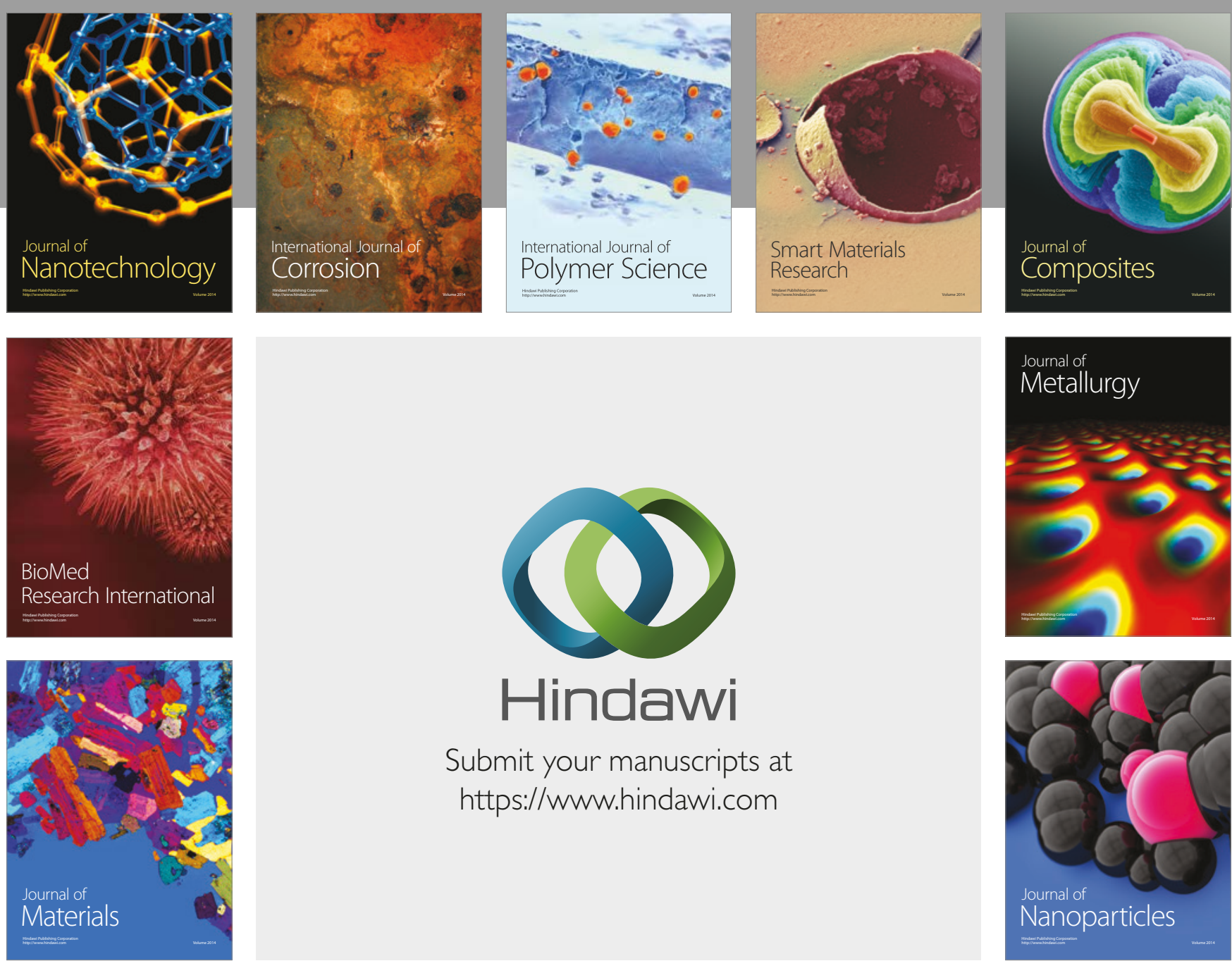

\section{Hindawi}

Submit your manuscripts at

https://www.hindawi.com
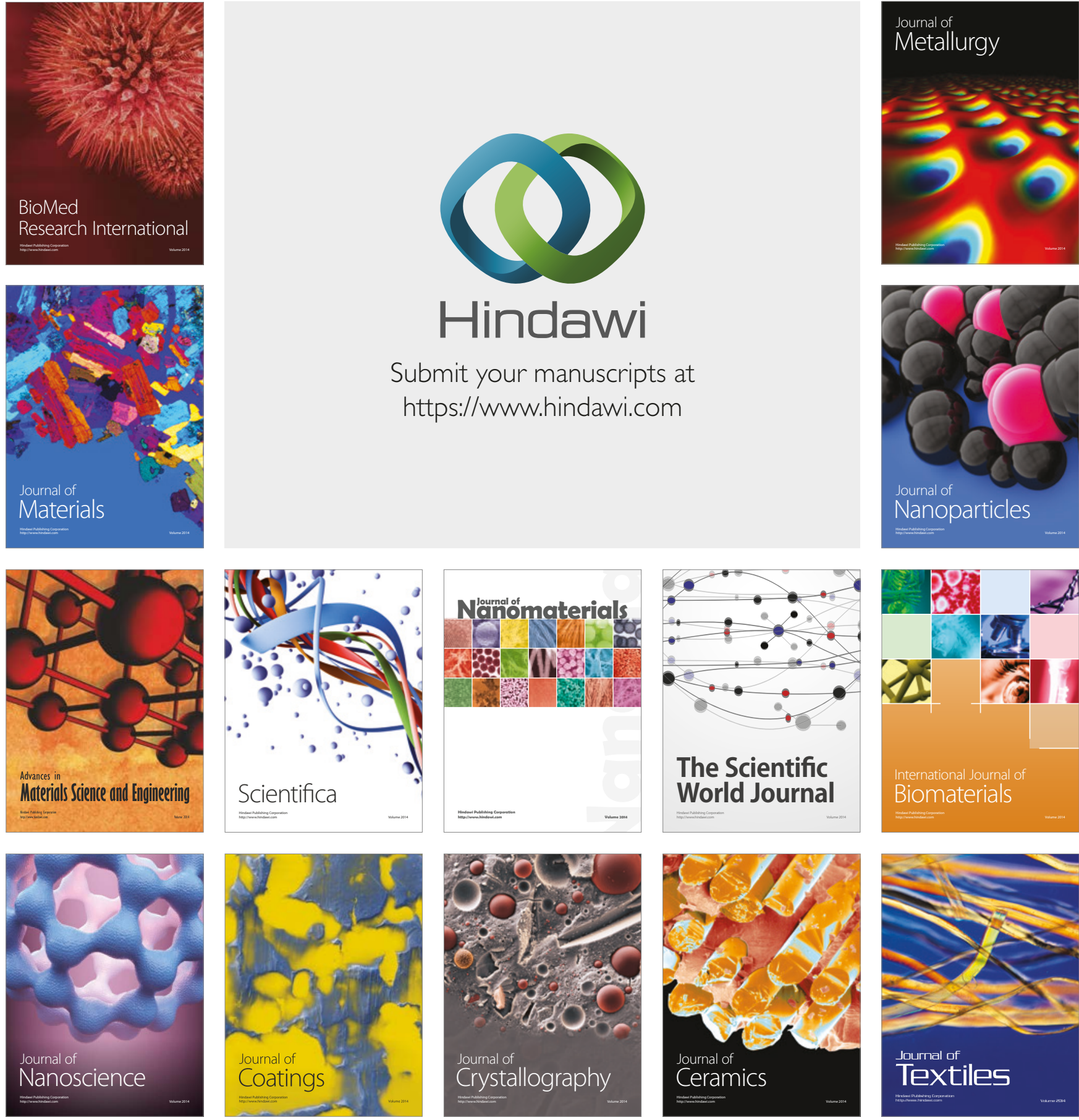

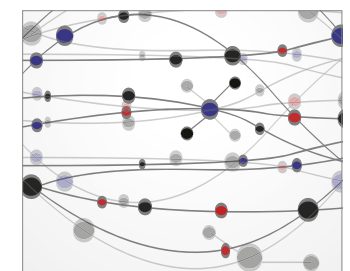

The Scientific World Journal
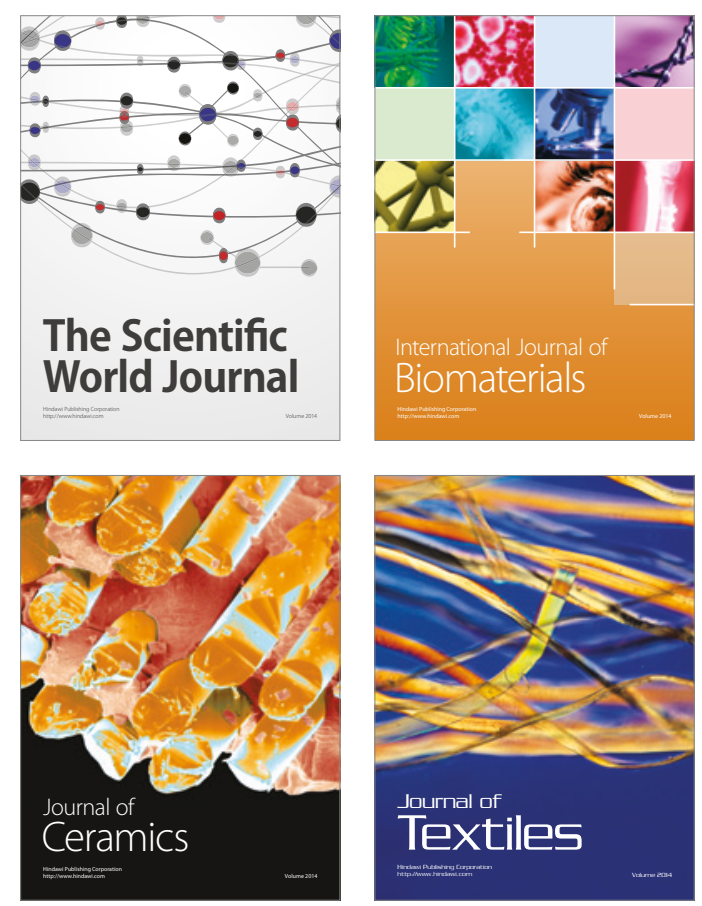